\title{
Morfologia e topografia do fígado e pâncreas de emas Rhea americana
}

\author{
Morphology and topography of the liver and pancreas of Rhea americana
}

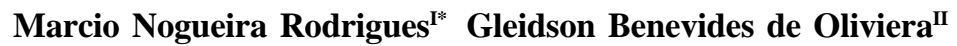 \\ Roberto Sávio Bessa da SilvaII José Fernando Gomes de Albuquerque ${ }^{\text {II }}$ \\ Maria Angelica Miglino ${ }^{I}$ Moacir Franco de Oliveira ${ }^{\text {I }}$
}

\section{RESUMO}

As emas são aves ratitas nativas do continente sul americano, são consideradas aves primitivas do ponto de vista filogenético que constituem um grupo altamente especializado. Este estudo buscou caracterizar macro e microscopicamente o fígado e pâncreas de emas. O material foi coletado no Centro de Multiplicação de Animais Silvestres (CEMAS), na cidade de Mossoró-RN, Brasil, (Registro IBAMA no 14.78912). Utilizaram-se 20 animais jovens com idade entre dois e seis meses independente do sexo. Em emas, o fígado se relacionava cranialmente com o ápice do coração, dorsalmente com os pulmões, esôfago e o proventrículo gástrico, caudalmente, com o ventrículo gástrico, o baço, o duodeno e parte do jejuno. Apresentava coloração vermelha escura e possuía apenas dois lobos, sendo o direito ligeiramente menor que o esquerdo. Histologicamente, era revestido por uma cápsula de tecido conjuntivo delgada e cada lóbulo hepático pôde ser identificado pela presença evidente de veias centrais, com muitos sinusoides comunicando-se com elas. O pâncreas, ventralmente, apresentava-se como uma fita fina, formado por um lobo dorsal e um lobo ventral. Longitudinalmente o pâncreas em emas localiza-se no mesentério dorsal desde o fígado até a flexura cranial do duodeno, mantendo-se preso às alças duodenais por ligamentos. Histologicamente, era composto por uma cápsula delgada de tecido conjuntivo denso, com discretos lóbulos separados por tecido conjuntivo capsular, compostos por estruturas tubuloalveolares e ductos. O fígado e pâncreas de emas apresentam padrão morfológico similar ao descrito para aves domésticas.

Palavras-chave: Rhea, fígado, pâncreas.

\section{ABSTRACT}

The rhea are ratites birds native of the South American continent, which are considered primitive birds from

\begin{abstract}
the standpoint of the phylogenetic group that is highly specialized.This study aimed to characterize gross and microscopically the liver and rhea pancreas. The material was collected in a Wild Animals Multiplication Center, Mossoró$R N$, Brazil, (Registration no 14.78912 IBAMA). It was used 20 young animals aged between two and six months independent of sex. In the rhea the liver is related to the cranial apex of the heart, dorsally with the lungs, esophagus and gastric proventriculus, caudally with the gastric ventricle, the spleen, the duodenum and part of the jejunum. It was dark red color and had only two lobes, being the right lobe slightly smaller than the left. Histologically was lined by a thin connective tissue capsule and each lobe liver could be clearly identified by the presence of central veins, with sinusoids communicating with the veins. The pancreas, ventrally, showed a thin tape formed by a dorsal lobe and a ventral lobe. Longitudinally the pancreas in rhea is located in the dorsal mesentery since the liver until the cranial duodenal flexure, remaining connected the duodenal handles by ligaments. Histologically was composed of a thin capsule of dense connective tissue, with discrete lobules separated by capsular connective tissue, composed of tubuloalveolares structures and pipelines. The liver and pancreas of rhea have morphology similar to that described for domestic poultry.
\end{abstract}

Key words: Rhea, liver, pancreas.

\section{INTRODUÇÃO}

Classificadas como aves do grupo das ratitas, as emas são aves do continente americano que se caracterizam por possuírem grande porte, coloração cinza, com um grupo de penas pretas na região peitoral,

IFaculdade de Medicina Veterinária e Zootecnia (FMVZ), Universidade de São Paulo (USP), Rua Professor Orlando Marques de Paiva, 87, 05508-270, São Paulo, SP, Brasil. E-mail: marcio_medvet@hotmail.com.br. *Autor para correspondência.

IIPrograma de Pós-graduação em Ciência Animal, Universidade Federal Rural do Semiárido (UFERSA), Mossoró, RN, Brasil. 
sem dimorfismo sexual, sendo que o macho assume as funções de incubação e cuidados com a prole (SICK, 1985). De acordo com SALES et al. (2000), a criação de emas em cativeiro data de 1800 . No entanto, estudos relacionados ao comportamento dessas aves ainda são muito pobres em comparação com outras criações de ratitas, como, por exemplo, o avestruz.

Nas duas últimas décadas, tem aumentado o interesse da população pelo consumo de carne de animais silvestres, associado ao fato de melhoria da alimentação, o que tem despertado curiosidade de produtores pela criação comercial de emas (LUENGO et al., 2000; SALES et al., 2000). Vários estudos vêm sendo realizados em emas, com o intuito de se conhecer a morfologia dessa ave, PARIZZI et al. (2007; 2008), a qual se apresenta com ovários e ovidutos, FORTES et al. (2009), com sangue periférico, SANTOS et al. (2011), com órgãos genitais, cloaca e língua, são alguns exemplos. AMBRÓSIO et al. (2001) descrevem que as glândulas anexas do aparelho digestório das emas são o fígado e pâncreas.

O estudo da morfologia do fígado e pâncreas torna-se importante uma vez que esses órgãos atuam diretamente na fisiologia da digestão. NITSAN et al. (1991) citam que, em galinhas, logo após o nascimento e com o início da alimentação, a relação de crescimento entre os segmentos do trato gastrintestinal e o crescimento do corpo é alométrica. Segundo os autores, o pâncreas e o intestino aumentam de peso quatro vezes e o fígado duas vezes mais que o peso do corpo, durante a primeira semana de vida. FIGUEIREDO et al. (2006), em estudos com fígado de avestruz, cita que o aumento de interesse pelos animais selvagens tem gerado uma busca pela pesquisa, pois, em muitos desses animais, ainda não se conhece completamente sua biologia e as características morfológicas de vários órgãos.

Existem poucos estudos sobre o fígado de aves (COLVILLE \& BASSERT, 2002) em tratado de clínica, alguns têm avaliado galinhas (SCHWARZE, 1972; GETTY, 1981; DYCE \& SACK, 1997), pombos (NICKEL et al., 1977) e avestruzes (BEZUIDENHOULT, 1999; MORINI et al., 2002). BENEZ (2004), ao estudar aves, em geral, afirma que o fígado e o pâncreas são órgãos significantes do seu organismo, já que tem funções metabólicas importantes. Segundo FIGUEIREDO et al. (2006), em estudos com avestruzes, o lobo direito é maior que o esquerdo, indivisível e não há vesícula biliar. Microscopicamente, STORNELLI et al. (2006), em avestruzes, relatam que, no fígado, pode ser observado um largo ducto que se abre na luz do duodeno e KADHIM et al. (2010), em avestruzes, citam que o pâncreas é recoberto por uma fina cápsula de tecido conjuntivo frouxo que emite septos que o dividem em lóbulos.

Nesse sentido, o estudo da morfologia do fígado e pâncreas em emas é fundamental para o posterior entendimento da fisiologia dessas aves e melhoria na formulação de rações específicas para elas.

\section{MATERIAL E MÉTODOS}

Foram utilizadas nesta pesquisa 20 emas jovens, que vieram a óbito por causas naturais, entre os dois e seis meses de vida, independente do sexo. Os animais foram oriundos do Centro de Multiplicação de Animais Silvestres (CEMAS), na cidade de Mossoró, $\mathrm{RN}$, Brasil, registrado junto ao IBAMA como criadouro científico sob o número 14.78912.

Foram utilizados quinze animais para as análises macroscópicas e cinco para as microscópicas do fígado e do pâncreas. Os animais foram incisados medianamente no sentido crânio-caudal partindo do vértice da mandíbula até a base da cloaca, para exposição das vísceras abdominais. Em seguida, o figado e pâncreas foram expostos para caracterização morfológica. Os animais foram fixados com solução aquosa de formol a $10 \%$, através de perfusão na musculatura e cavidade visceral, por um período mínimo de 48 horas até a completa fixação, sendo, posteriormente, dissecados e, em seguida, o material foi fotodocumentado em fotomicroscópio Nikon Eclipse E-800.

Para as análises microscópicas do fígado e pâncreas, fragmentos com aproximadamente $0,5 \mathrm{~cm}$ foram coletados e imersos em solução fixadora de formaldeído a $10 \%$ tamponado com solução fosfato de sódio $0,1 \mathrm{M}, \mathrm{pH} 7,2 \mathrm{a} 4^{\circ} \mathrm{C}$. Após fixação, procedia-se à desidratação em uma série de etanóis em concentrações crescentes (de 70 a 100\%), seguida de diafanização em xilol e inclusão em similar de parafina histológica - Ervplast. Foram obtidos cortes com $5 \mu \mathrm{m}$ de espessura em micrótomo LEICA 2165, que eram então corados com Hematoxilina-eosina. A coleta do material, os cortes histológicos, bem como a preparação e coloração das lâminas foram realizadas com base na metodologia descrita por (TOLOSA et al., 2005).

As estruturas foram denominadas com base no que preconiza o Handbook of avian anatomy: nomina anatomica avium e a Veterinary Histological Nomenclature, editado pelo International Commitee on Avian Anatomical Nomenclature, editado pelo International Commitee on Avian Anatomical Nomenclature, World Association of Veterinary Anatomists (1994).

\section{RESULTADOS E DISCUSSÃO}

O fígado de emas possui dois lobos, sendo um direito e um esquerdo, unidos cranialmente na linha média, com cor vermelho escura. Tais resultados são semelhantes aos citados por SCHRÖDER \& KRAHMER (1979), BAILEY et al. (1997) e CANO (2009), sobretudo, quando esses autores citam a lobação do fígado de aves. BAILEY et al. (1997) e 
FIGUEIREDO et al. (2006) descrevem o fígado como uma estrutura dividida em quatro lobos, em aves gruiformes e avestruzes, respectivamente. SCHWARZE (1972) descreveu a morfologia do fígado de galinhas apresentando quatro lobos hepáticos diferentes do encontrado em emas e para outras aves pelos autores supracitados.

Em emas, verificou-se que o lobo direito é ligeiramente menor que o esquerdo e disposto mais cranial que este. A maior parte da superfície parietal é convexa e lisa, sendo que características semelhantes foram observadas por NICKEL et al. (1977) no fígado de pombos e por COLVILLE \& BASSERT (2002), os quais afirmam que, em aves em geral, observa-se a presença de dois lobos, o direito e o esquerdo.

Cranialmente se relaciona com o ápice do coração. Dorsalmente, com os pulmões, esôfago e o proventrículo gástrico, caudalmente, com o ventrículo gástrico, o baço, o duodeno e parte do jejuno (Figura 1A). Em alguns animais, aqueles mais jovens, a vesícula biliar pôde ser observada (Figura 1B) e, em todos os casos, apresentou cor castanha. Esse resultado é semelhante ao citado por SCHWARZE (1972) no fígado de galinhas, mas difere do citado por NICKEL et al. (1977) para pombos, quando afirmam que o fígado não possui processo intermédio nem vesícula biliar. COLVILLE \& BASSERT (2002) em aves em geral, MORINI et al. (2002), FIGUEIREDO et al. (2006) em avestruzes e MATSUMOTO et al. (2009) no periquito australiano, não fazem nenhuma observação sobre o comportamento da vesícula biliar, em seus estudos.

Em corte histológico, verificou-se que o fígado era revestido por uma cápsula de tecido conjuntivo delgada. Disposta sobre ela, foi observada uma fina camada de células mesoteliais que juntas constituem a serosa do órgão, tais resultados corroboram o citado por BACHA \& BACHA (2003) em tradado de histologia para aves em geral. Em emas, observou-se que cada lóbulo hepático pôde ser identificado pela presença evidente de veias centrais, em que, em muitos casos, eram observados sinusoides que com elas se comunicavam, semelhante ao descrito

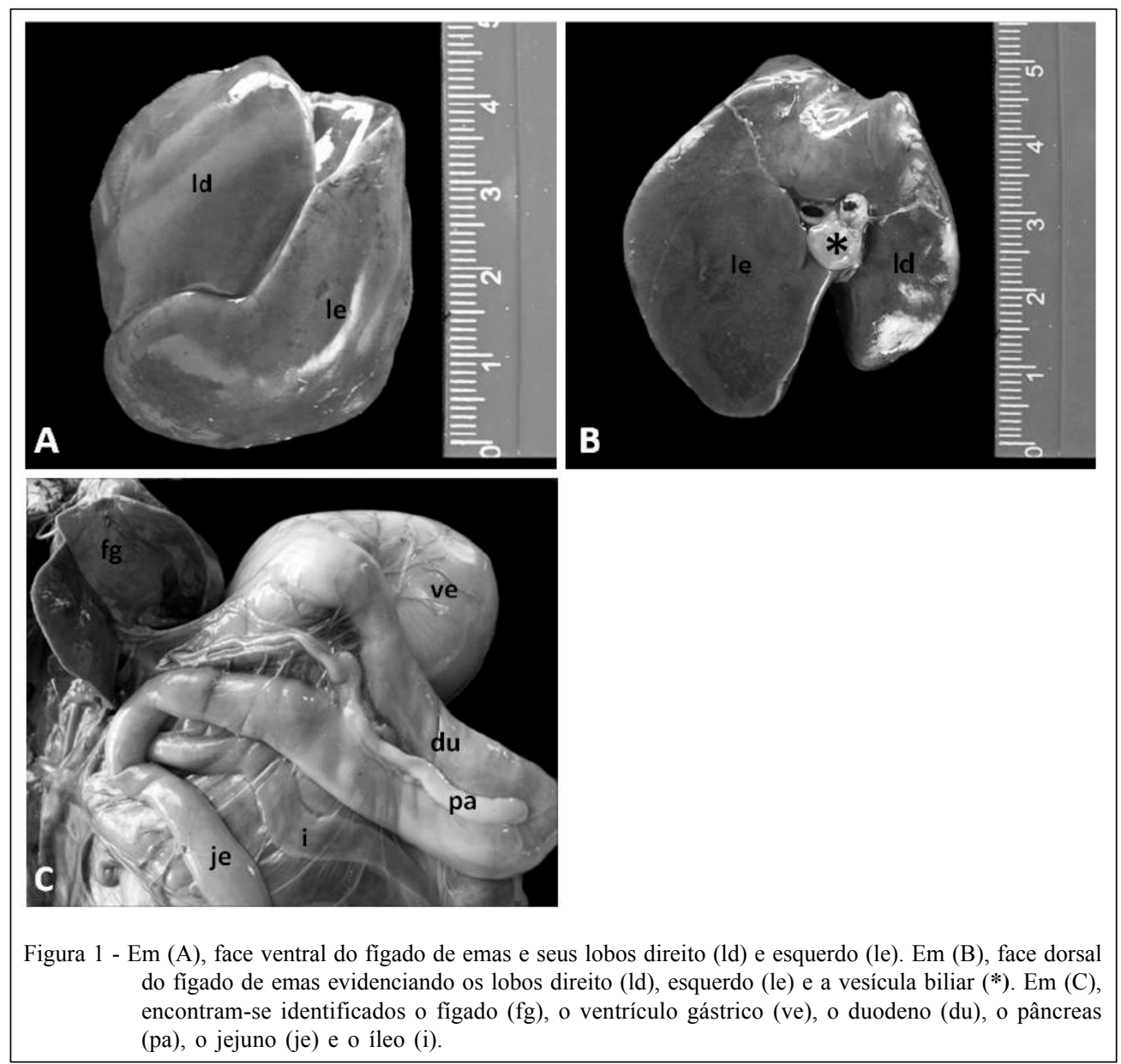

Ciência Rural, v.42, n.3, mar, 2012. 
por MATSUMOTO et al. (2009) para o periquito australiano. O tamanho, forma e limite celular dos hepatócitos nos cortes histológicos permitiram diferenciá-los com facilidade das demais estruturas.

Em alguns cortes, foram identificados, em emas, transversalmente, o ducto biliar, composto por epitélio cúbico simples. A vesícula biliar apresentouse semelhante à de mamíferos com mucosa revestida por um epitélio colunar simples (BACHA \& BACHA, 2003). (Figura 2).

Quanto ao pâncreas, observou-se que nas emas era longo, achatado e de coloração amarelo claro. AMBRÓSIO et al. (2001) e CANO (2009) afirmam que o pâncreas possui três lobos distintos. CATROXO (1997), em estudos com cardeal vermelho, citam o pâncreas como estrutura multilobulada. Em emas, observou-se que, ventralmente, o pâncreas se apresentava como uma fita fina, formado por um lobo dorsal e um lobo ventral semelhante ao citado por BAILEY et al. (1997) e diferente do encontrado pelos autores supracitados. Longitudinalmente, o pâncreas em emas localiza-se no mesentério dorsal desde o fígado até a flexura cranial do duodeno, mantendo-se preso às alças duodenais por ligamentos. Ao longo dessas alças, ele emite vários ductos, discordando do encontrado por NICKEL et al. (1977) que relataram haver três diferentes ductos pancretáticos nas aves e nos pombos, dois dos quais surgem de um ventral e do lobo dorsal. Difere também do encontrado por GULMEZ (2003), quando afirma que, no ganso, há apenas dois ductos $\mathrm{e}$ de LIU et al. (1998) que afirmam que no pato existem apenas dois ductos (Figura 1C). Os resultados macroscópicos encontrados em emas são semelhantes aos encontrados por KADHIM et al. (2010) em galinhas, quanto a localização, lobação e presença de vários ductos dispostos através do duodeno (Figura 1C).

Microscopicamente, o pâncreas de emas corresponde a uma estrutura composta por uma cápsula delgada de tecido conjuntivo frouxo, corroborando o citado por KADHIM et al. (2010) em galinhas. Essa camada de tecido conjuntivo emitia septos que dividiam o pâncreas em lóbulos caracterizados como tecido conjuntivo capsular, compostos por estruturas tubuloalveolares e ductos. Nesse tecido conjuntivo, foram observados septos que dividíam o pâncreas em lóbulos. Vasos sanguíneos, linfáticos e ductos excretores foram observados.

As células glandulares eram compostas principalmente por unidades exócrinas formadas por células piramidais e a parede dos ductos eram compostas por epitélio cúbico (Figura 3). Foram encontradas poucas ilhotas de Langerhans e estas eram irregulares. Os resultados histológicos encontrados em emas são semelhantes aos citado por HODGES (1974) em galinhas domésticas, BAUMEL (1993) na nômina anatômica aviária e por KADHIM et al. (2010) em galinhas campestres.

O fígado e pâncreas das emas apresentam padrão morfológico similar ao descrito para aves domésticas, quando comparado os resultados estabelecidos na literatura sobre aves, BACHA \& BACHA (2003), ILLANES et al. (2006) e SAMUELSON (2007), uma vez que referem-se à presença de uma cápsula de revestimento, presença de ductos biliares e
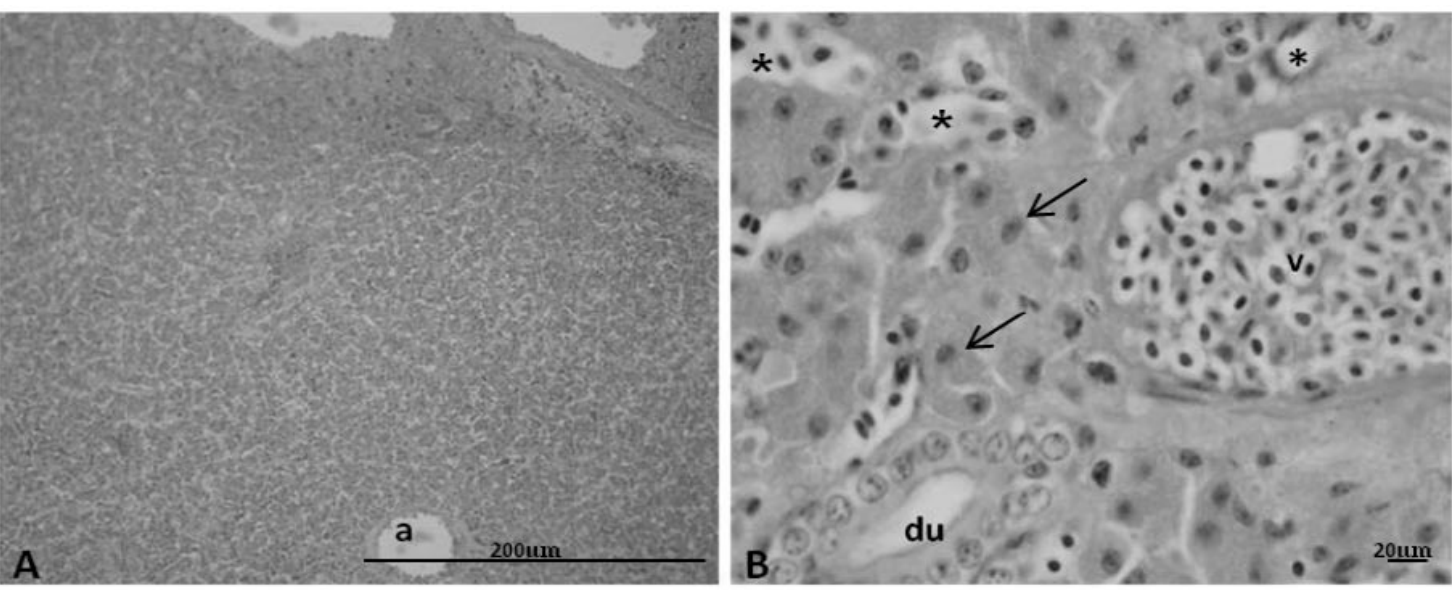

Figura 2 - Fotomicrografia de corte histológico do fígado de emas. Em (A), observa-se a artéria hepática (a) em corte transversal. Em (B), estão indicados um ramo da veia hepática (v), um corte do ducto biliar (du) e a presença de sinusoides $(*)$. Hematoxilina -eosina. 


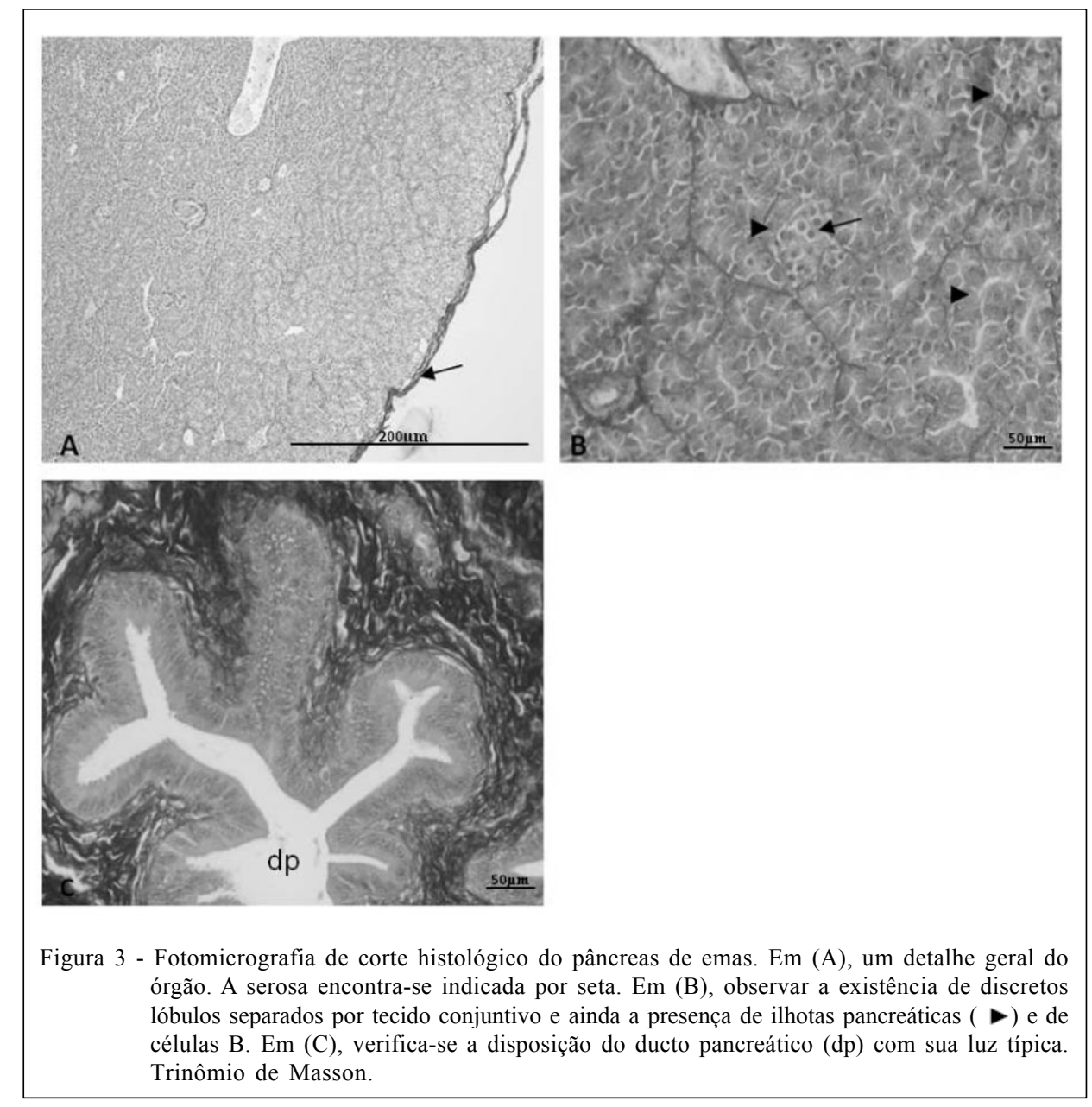

hepatócitos típicos no fígado e no pâncreas, podem ser identificados elementos como: glândulas tubuloalveolares, vasos sanguíneos e ductos de excreção, além da delgada cápsula de tecido conjuntivo frouxo.

Com este estudo, conclui-se que poucas são as diferenças morfológicas relacionadas ao padrão anátomo histológico do fígado e pâncreas de emas, quando comparadas as outras aves e principalmente a outras ratitas como o avestruz. Contrastando o que normalmente se afirma em relação à ausência da vesícula biliar, nos animais estudados, uma estrutura biliar típica de cor castanha foi identificada macro e microscopicamente. Tais observações trazem informações relevantes quanto à anatomia dessas aves com o intuito de melhorar o estudo nutricional e fisiológico por outros pesquisadores.

\section{COMITÊ DE ÉTICA E BEM-ESTAR ANIMAL} 14.78912

\section{REFERÊNCIAS}

BACHA, W.J.; BACHA, L.M. Atlas colorido de histologia veterinária. 2.ed. São Paulo: ROCA, 2003. 457p.

BAILEY, T.A. et al. Comparative morphology of the alimentary tract and its glandular derivates of captive bustards. Journal of Anatomy, v.191, p.387-398, 1997. Disponível em: <http:// www.ncbi.nlm.nih.gov/pmc/articles/PMC1467696/>. Acesso em: 15 de mar. 2011. doi: 10.1046/j.1469-7580.1997.19130387.x.

BAUMEL, J.J. Handbook of avian anatomy: Nomina Anatomica Avium. 2.ed. Cambridge, MA, USA: Nuttall Ornithological Club, 1993. 779p

BENEZ, S.M. Aves. 4.ed. São Paulo: Tecmed, 2004. 600p.

BEZUIDEnhout, A.J. Anatomy. In: DEEMING, D.C. The ostrich: biology, production and health. London: CABI, 1999. p.13-49.

CANO, F.G. Anatomía específica de aves: aspectos funcionales y clínicos. Unidad Docente de Anatomía y Embriologia. Facultad de Veterinária. Universidad de Murcia. Disponível em: <http://www.um.es/anatvet/apr/aaves>. Acesso em: 26 mar. 2009.

Ciência Rural, v.42, n.3, mar, 2012. 
CATROXO, M.H.B. et al. Histological aspects of the stomach (proventriculus and gizzard) of the red-capped cardinal (Paroaria gularis gularis, LINNAEUS, 1766). Revista chilena de anatomia., v.15, n.1, p.19-27, 1997. Disponível em: <http:// www.scielo.cl/scielo.php?pid=S071698681997000100003\&script =sci abstract\&tlng=en>. Acesso em: 15 mar. 2009. doi: 10.4067/ S0716-98681997000100003

COLVILLE, T.; BASSERT, J.M. Clinical anatomy \& physiology for veterinary technicians. Moulsby: Elsevier, 2002. $452 p$

DYCE, K.; SACK, W.W.K. Textbook of veterinary anatomy. Philadelphia: Saunders, 1997. 663p.

FIGUEIREDO, M.A. et al. Aspectos morfológicos e topográficos do fígado de avestruz (Struthio camelus). Revista Portuguesa de Ciências Veterinárias, v.101, p.557-558, 2006. Disponível em: <http://www.fmv.utl.pt/spcv/PDF/ pdf6 2006/557 558 41 43.pdf>. Acesso em: 10 fev. 2009.

FORTES, E.A.M. et al. Morfologia das células do sangue periférico em emas (Rhea americana). Brazilian Journal Veterinary Research and Animal Science, v.46, n.3, p.215221, 2009. Disponível em: <http://www.revistasusp.sibi.usp.br/ pdf/bjvras/v46n3/v46n3a07.pdf>. Acesso em: 15 mar. 2009.

GETTY, R. Anatomia dos animais domésticos. 5.ed. Rio de Janeiro: Interamericana, 1981. 1863p.

GULMEZ, N. Are glands present in goose pancreatic ducts? A light microscope study. Journal of the Pancreas, v.4, n.3, p.125-128, 2003. Disponível em: <http://www.joplink.net/prev/ 200305/200305 03.pdf>. Acesso em: 16 mar. 2009.

HODGES, R.D. The histology of the fowl. London: Academic, 1974. p.35-88. Disponível em: <http:// www.ncbi.nlm.nih.gov/pmc/articles/PMC1697011/>. Acesso em: 15 mar. 2009.

ILLANES, J. et al. Descripción histológica de los diferentes segmentos del aparato digestivo de avestruz (Struthio camelus var. domesticus). International Journal of Morphology, v.24, n.2, p.205-214, 2006. Disponível em: <http:// www.biotemas.ufsc.br/volumes/pdf/volume223/149a155.pdf> Acesso em: 15 de mar. 2009.

INTERNATIONAL COMMITEE ON VETERINARY GROSS ANATOMICAL NOMENCLATURE. Nômina anatômica veterinária. 4.ed. Ithaca: Word Association on Veterinary Anatomists, 1994. 190p

INTERNATIONAL COMMITEE ON VETERINARY HISTOLOGICAL NOMENCLATURE. Nômina histological (Together with Nômina anatômiva veterinária). 2.ed. rev. Zurich: Word Association on Veterinary Anatomists, 1994. 190p.

KADHIM, K.K. et al. Morphological study of pancreatic duct in red jungle fowl. African Journal of Biotechnology, v.9, n.42, p.7209-7215, 2010. Disponível em: <http:// www.academicjournals.org/AJB/PDF/pdf2010/180ct/ Kadhim\%20et\%20al.pdf>. Acesso em: 20 nov. 2010.

LIU, J.W. et al. Gross anatomy of the pancreatic lobes and ducts in six breeds of domestic ducks and six species of wild ducks in china. Anatomia Histologia Embryologia v. 27, p.413-417, 1998. Disponível em: <http://www.ncbi.nlm.nih.gov/ pubmed/9972650>. Acesso em: 30 mar. 2009.

LUENGO, M.C. et al. Análisis nutricional y evaluación sensorial de la carne de choique. In: Actas del taller sobre conservación y manejo del choique en Patagonia. Bariloche: INTA, 2000. p.33-34.

MATSUMOTO, F.S. et al. Topografia e morfologia das vísceras do Periquito-Australiano (Melopsittacus undulatus, SHAW 1805). Ciência Animal Brasileira, v.10, n.4, p.1263-1270, 2009. Disponível em: <http://www.revistas.ufg.br/index.php/ vet/article/view/3776>. Acesso em: 02 abr. 2009.

MORINI, A. et al. Estudo da topografia e da lobação do fígado de avestruzes. In: CONGRESSO BRASILEIRO DE ANATOMIA, 20., 2002, Maceió, Al. Anais... Maceió: SBA, 2002. p. 75 .

NICKEL, R. et al. The anatomy of the domestic birds. 2.ed. Berlin: Verlag Paul Parey, 1977. 202p

NITSAN, Z. et al. Growth and development of the digestive organs and some enzymes in broiler chicks after hatching. Brazilian Poultry Science, v.32, p.515-523, 1991 Disponível em: <http://www.ncbi.nlm.nih.gov/pubmed/ 1716507>. Acesso em: 02 de abr. 2009.

PARIZZI, R.C. et al. Macroscopic and microscopic anatomy of the oviduct in the sexually mature rhea (Rhea americana). Anatomia, Histologia, Embryologia, v.37, p.169-176, 2008. Disponível em: <http://www.ncbi.nlm.nih.gov/pubmed/ 18070241>. Acesso em: 05 abr. 2009.

PARIZZI, R.C. et al. Morfologia do ovário de ema (Rhea americana). Pesquisa Veterinária Brasileira, v.27, p.8994, 2007. Disponível em: <http://www.scielo.br/pdf/pvb/v27n3/ 02.pdf>. Acesso em: 05 abr. 2009.

SALES, J. et al. Diurnal time-activity budget of adult Greater Rheas (Rhea Americana) in farming environment. Archiv Geflugelk, v.64, n.5, p.207-210, 2000. Disponível em: <http:/ /www.mendeley.com/research/diurnal-timeactivity-budget-adultgreater-rheas-rhea-americana-farming-environment/>. Acesso em: 03 abr 2010.

SANTOS, T.C. Morfologia dos orgãos genitais masculinos e da cloaca da ema (Rhea americana americana). Pesquisa Veterinária Brasileira, v.31, p.430-440, 2011. Disponível em: $<$ ht tp://www.scielo.br/scielo.php? pid=S 0100 736X2011000500011\&script $=$ sci_arttext $>$. Acesso em: 15 mar. 2011.

SANTOS, T.C. Light and scanning electron microcopy study of the tongue in rhea (Rhea americana americana). Zoological Science, v.28, p.41-46, 2011. Disponível em: <http:// www.ncbi.nlm.nih.gov/pubmed/21186946>. Acesso em: 15 mar. 2011.

SAMUELSON, D.A. Texbook of veterinary histology. Missouri: Elsevier, 2007. 546p.

SICK, H. Ornitologia brasileira. Brasília: [s. n.], 1985. V.1, 482p.

SCHWARZE, E. Compêndio de anatomia veterinária. Anatomia de las aves. Zaragoza: Acribia, 1972. Tomo V.

SCHRÖDER, L.; KRAHMER, R. Anatomia de los animales domésticos. 2.ed. Zaragoza: Acribia, 1979. 339p.

STORNELLI, M.R. et al. Morphological and histological study of the ostrich (Struthio camelus L.) liver and biliary system. International Journal Anatomy and Embriology, v.111, n.1, p.1-7, 2006. Disponível em: <http://www.ncbi.nlm.nih.gov/ pubmed/16736712>. Acesso em: 10 mar. 2009.

TOLOSA, E.M.C. et al. Manual de técnicas para histologia normal e patológica. 3.ed. São Paulo: Manole, 2005. 482p. 